\title{
Neuigkeiten von der RöFo
}

Liebe Leserinnen, liebe Leser,

wir möchten Sie darüber informieren, dass Herr Professor Johannes Lammer seine Mitherausgeberschaft bei der RöFo beendet hat und das Staffelholz, stellvertretend für die Interventionelle Radiologie, nun an Herrn Professor Arno Bücker aus Homburg/Saar übergeben hat.

Herr Professor Lammer hat die RöFo 18 Jahre lang tatkräftig und konstruktiv begleitet: ab 1996 zunächst im erweiterten Herausgebergremium - in der Gruppe der „Mitwirkenden“ - und seit dem Jahr 2002 als Mitherausgeber der RöFo. Wir bedanken uns sehr herzlich bei Herrn Professor Lammer für die vertrauensvolle und erfolgreiche Zusammenarbeit wünschen ihm persönlich und für alle seine neuen Vorhaben alles Gute und viel Erfolg!

Wir freuen uns sehr, dass Herr Professor Bücker unsere Einladung ins Herausgebergremium der RöFo angenommen hat und wir mit ihm einen international angesehenen Vertreter der Interventionellen Radiologie für die Zeitschrift gewinnen konnten. Nachfolgend haben Sie die Gelegenheit, Professor Bücker in einer kurzen Vorstellung kennenzulernen.

Herr Professor Dr. med. Arno Bücker wurde 1965 in Remscheid (Geburtsstadt von W.C. Röntgen) geboren. Das Studium der Humanmedizin absolvierte er von 1985 bis 1992 an der Rheinischen Friedrich Wilhelm Universität, Bonn. Von Juni bis Oktober 1990 verbrachte er einen Forschungsaufenthalt am Institut der UCSF Radiologic Imaging, California, USA. Die Promotion erfolgte im Oktober 1992. In diesem Jahr erlangte er auch den Abschluss des amerikanischen Staatsexamens für Ausländer (ECFMG). Dem Abschluss der Facharztprüfung im Jahre 1998 folgte 1999 die Habilitation mit der Verleihung der Venia legendi für das Fach Diagnostische Radiologie. Die Habilitationsarbeit von Arno Bücker wurde mit dem Friedrich-Wilhelm-Preis der Rheinisch-Westfälischen Technischen Hoch- schule Aachen und im Jahre 2001 mit dem 3. Wilhelm-Conrad-Röntgen-Preis ausgezeichnet. Seit 1994 war Arno Bücker an der Klinik für Radiologische Diagnostik, RWTH Aachen, zunächst als wissenschaftlicher Assistent, dann ab dem Jahre 2000 als Oberarzt und ab 2002 als Leitender Oberarzt tätig. Ebenfalls in Aachen erfolgte 2003 die Ernennung zum apl. Professor sowie zum Leitenden Personaloberarzt und Stellvertreter des Klinikdirektors der Klinik für Radiologische Diagnostik. Von 2003 bis 2005 absolvierte er einen berufsbegleitenden Masterstudiengang, den er mit dem Master of Science in Hospital Administration abschloss.

Professor Bücker ist seit Juli 2006 Direktor der Klinik für Diagnostische und Interventionelle Radiologie am Universitätsklinikum des Saarlandes in Homburg/Saar. Er ist Mitglied zahlreicher nationaler und internationaler Fachgesellschaften und seit dem Mai 2014 Vorsitzender der Deutschen Gesellschaft für Interventionelle Radiologie (DeGIR). Außerdem seit 2014 Mitherausgeber von gefaessmedizin.net sowie Mitglied im Assistant Editorial Board von Investigative Radiology.

Professor Bückers Forschungsschwerpunkte liegen auf dem Gebiet der Interventionellen Radiologie und betreffen sowohl den vaskulären als auch den onkologischen Bereich. Darüber hinaus arbeitet er an der Implementierung von interventionellen Techniken unter MRT-Steuerung.

Herr Professor Bücker wird zweifellos ein wichtiger Ideengeber für die RöFo sein und wir freuen uns auf eine gute Zusammenarbeit mit ihm.

Rechtzeitig vor Drucklegung erreicht uns eine weitere Neuigkeit, die bereits mehrfach bei uns nachgefragt wurde: Der Impact Factor 2013 der RöFo beträgt 1,961.

\section{Herausgeber und Verlag}
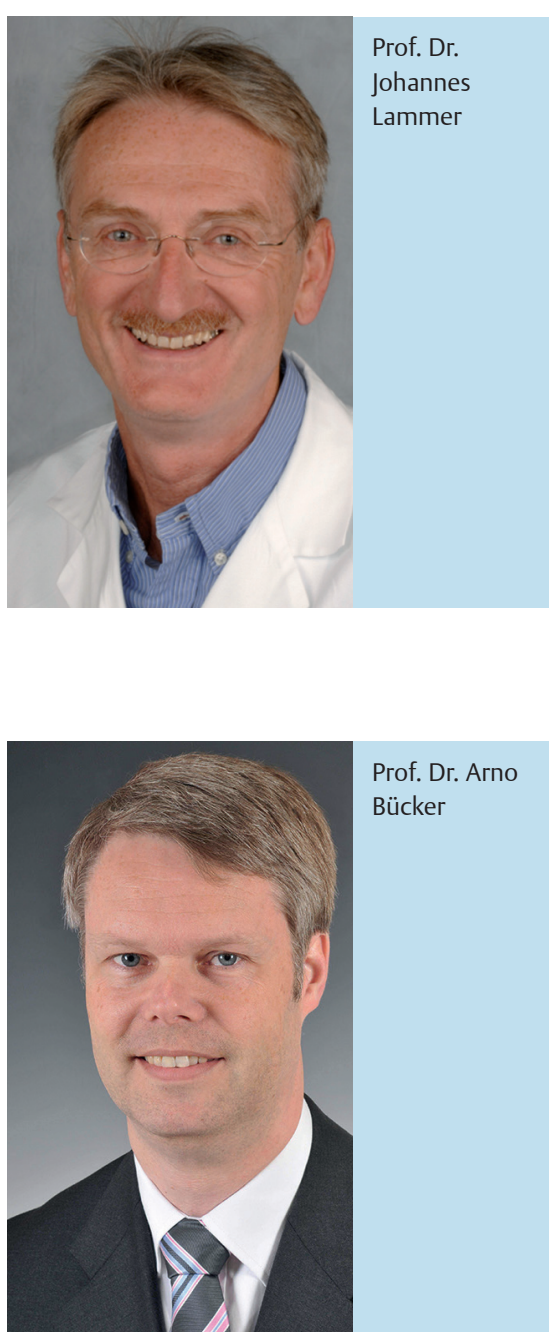